\title{
Performance Analysis of 12S-10P HEFSM with Various Flux Bridges
}

\author{
Nurul 'Ain Jafar', a , Erwan Sulaiman ${ }^{1, b}$ and Siti Khalidah Rahimi ${ }^{1, c}$ \\ ${ }^{1}$ Dept. of Electrical Power Engineering, Faculty of Electrical and Electronic Engineering, \\ University Tun Hussein Onn Malaysia, \\ P.O Box 86400, Parit Raja, Batu Pahat, MALAYSIA \\ aaienjafar@yahoo.com, berwan@uthm.edu.my, 'sitikhalidah17@gmail.com
}

Keywords:, flux switching machine, hybrid excitation, iron flux bridges.

\begin{abstract}
Flux switching machine (FSMs) with several advantages of robust rotor structure, high reliability, high efficiency and high torque density have been develop in recent years. Among several types of FSM, HEFSM gives extra advantage at variable flux capabilities suitable for higher load conditions. However, the developed C-Type has a problem of separated stator core which lead to difficulty in manufacturing design as well as flux leakage to the outer stator. In order to solve the problem, iron flux bridges have been introduced to the stator core. Because of that, the separated stator core becomes the single piece of core. In this paper, various topologies of iron flux bridges is introduced and overviewed. Performances of torque at various flux bridge is analyzed and compared. This analysis is verified by Finite Element Analysis (2D-FEA).
\end{abstract}

\section{Introduction}

Commonly, the flux switching machine (FSM) can be categorized into three groups. The first concept of FSM was founded in the middle of 1950's. The categories of FSM are consists of Permanent Magnet Flux Switching Machine (PMFSM), Field Excitation Flux Switching Machine (FEFSM) and Hybrid Excitation Flux Switching Machine (HEFSM). Both PMFSM and FEFSM has only PM and field excitation coil (FEC), respectively as their main flux sources whereas HEFSM combines both PM and FEC as their main flux sources. According to their theory of operation, HEFSM is getting more prominent lately.

HEFSM are those which use two excitation flux sources whereas utilize permanent magnets (PMs) as primary excitation meanwhile field coil excitation as a secondary source. The combination of advantages for both PM machines and wound field synchronous machines becomes goal behind the association of both sources that have been researched over many years. Conventionally, by controlling the armature winding current, PMFSMs can be operated beyond base speed in the flux weakening regions. In addition, the PM flux can also be counteracted by applying negative d-axis current. Besides, it gives the disadvantages of increase in copper loss and also reduced the efficiency. In addition, the other disadvantages are can reduced the power capability and also possible irreversible demagnetization of the PMs. HEFSM have the potential to improve the flux weakening and flux enhancing performance and efficiency.

Generally, hybrid excitation machine (HEM) can be classified into four categories according to the location of PM and FEC. The first type consist both PM and FEC are located at the rotor side [1,2], the second type consist the PM is in the rotor while the FEC is in the stator [3]. The third type the PM is in the rotor while the FEC is in the machine end [4,5]. Others, the last type is both PM and FEC are located in the stator. All HEMs mentioned in the first three consist of a PM in the rotor and can be categorized as "hybrid rotor-PM with FEC machines" while the final machine can be referred as "hybrid stator-PM with FEC machines" [6-9].

Various topologies of HEFSMs have been developed and investigated as shown in Fig.1 [10,11]. Fig. 1(a) illustrates 12S-10P HEFSM which consist of 10 salient rotor pole numbers while the stator core consist of 12 modular C-Type laminated segments placed next to each other with circumferentially magnetized PMs and FEC placed in between them. The arrangement of PMs and FEC is at the same alignment. In addition, this design is build up of 12 DC FEC slots and 12 
armature coil (AC) slots. Furthermore, the component part that involved likes PMs, FEC and AC are rectangle in shape thus can make the proposed motor has a very simple structure. This topology has an interest due to their simple and robust rotor design and high torque density. However, the developed C-Type has a problem of separated stator core which lead to difficulty in manufacturing design as well as flux leakage to the outer stator. In order to solve the problem, iron flux bridges have been introduced to the stator core. Because of that, the separated stator core becomes the single piece of core.

The design requirements, restrictions and specifications for the proposed HEFSM are similar for conventional HEV as listed in Table I. The corresponding electrical restrictions to the inverter such as maximum DC bus voltage and maximum inverter current are set to $650 \mathrm{~V}$ and $360 \mathrm{~A}_{\text {rms }}$, respectively. Assuming that only a water cooling system is employed as the cooling system of the machine, the limit of the both armature current density, $\mathrm{J}_{\mathrm{a}}$ and FEC current density, $\mathrm{J}_{\mathrm{e}}$ are restricted to $30 \mathrm{~A}_{\mathrm{rms}} / \mathrm{mm}^{2}$ and $30 \mathrm{~A} / \mathrm{mm}^{2}$, respectively. The outer diameter $269 \mathrm{~mm}$ and stack length $84 \mathrm{~mm}$ of main parts of this design machine are identical with conventional motor used in HEV. Commercial FEA package, JMAG-Studio ver.13.0, released by Japanese Research Institute (JRI) is used as 2D-FEA solver in this design.

\section{Various Bridges Topologies}

In order to overcome this drawback, several arrangements of iron flux bridges with $0.5 \mathrm{~mm}$ thickness are designed to the initial C-Type HEFSM as shown in Fig. 2. The main objectives of adding the iron flux bridges to the initial design motor not only can solve the manufacture process

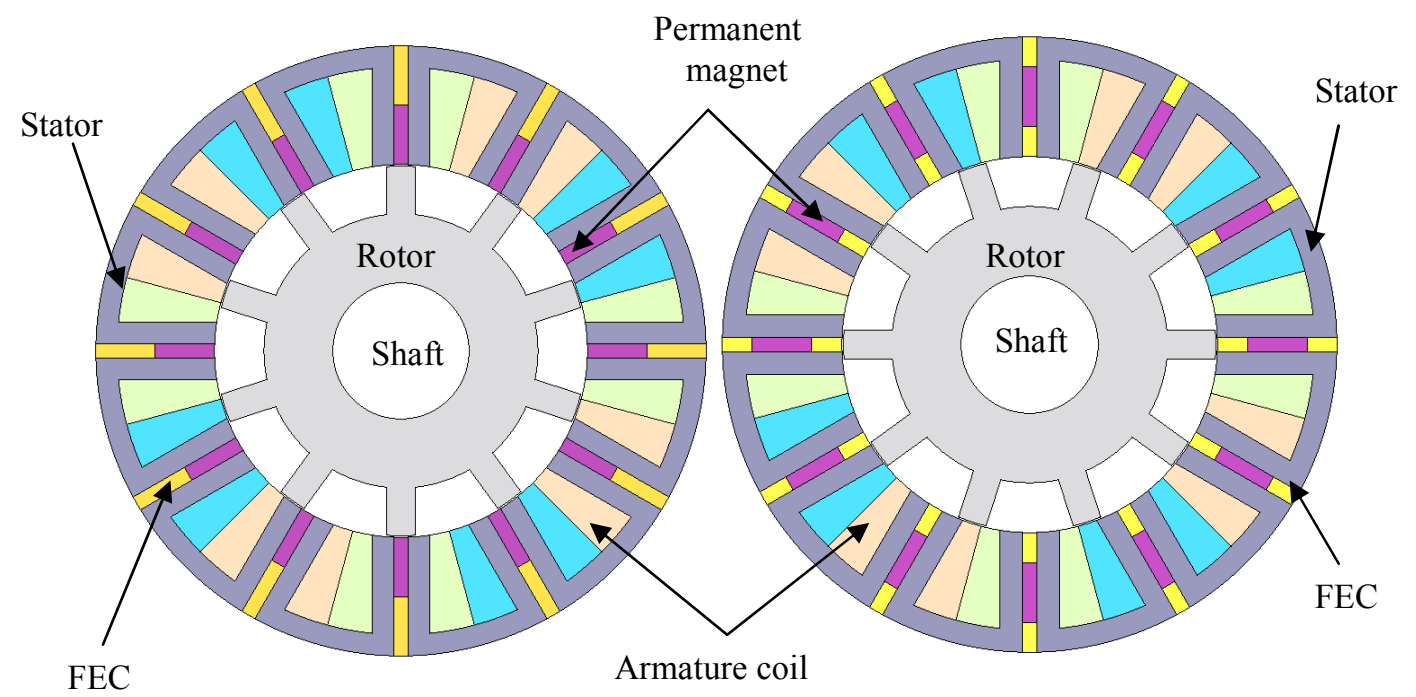

(a)

Fig. 1. 12S-10P HEFSM

(b)

Table 1. HEFSM motor design specifications and limitations

\begin{tabular}{|l|c|}
\hline \multicolumn{1}{|c|}{ Items } & HEFSM \\
\hline Maximum DC voltage $(\mathrm{V})$ & 650 \\
\hline Maximum current $\left(\mathrm{A}_{\mathrm{rms}}\right)$ & 360 \\
\hline Maximum $\mathrm{J}_{\mathrm{a}}\left(\mathrm{A}_{\mathrm{rms}} / \mathrm{mm}^{2}\right)$ & 30 \\
\hline Maximum $\mathrm{J}_{\mathrm{e}}\left(\mathrm{A} / \mathrm{mm}^{2}\right)$ & 30 \\
\hline Stator outer diameter $(\mathrm{mm})$ & 269 \\
\hline Motor stack length $(\mathrm{mm})$ & 84 \\
\hline Diameter of shaft $(\mathrm{mm})$ & 30 \\
\hline Air-gap $(\mathrm{mm})$ & 0.7 \\
\hline PM volume $(\mathrm{kg})$ & 1.3 \\
\hline Max. torque $(\mathrm{Nm})$ & 303 \\
\hline Max. power $(\mathrm{kW})$ & 123 \\
\hline Width of iron flux bridges $(\mathrm{mm})$ & 0.5 \\
\hline
\end{tabular}



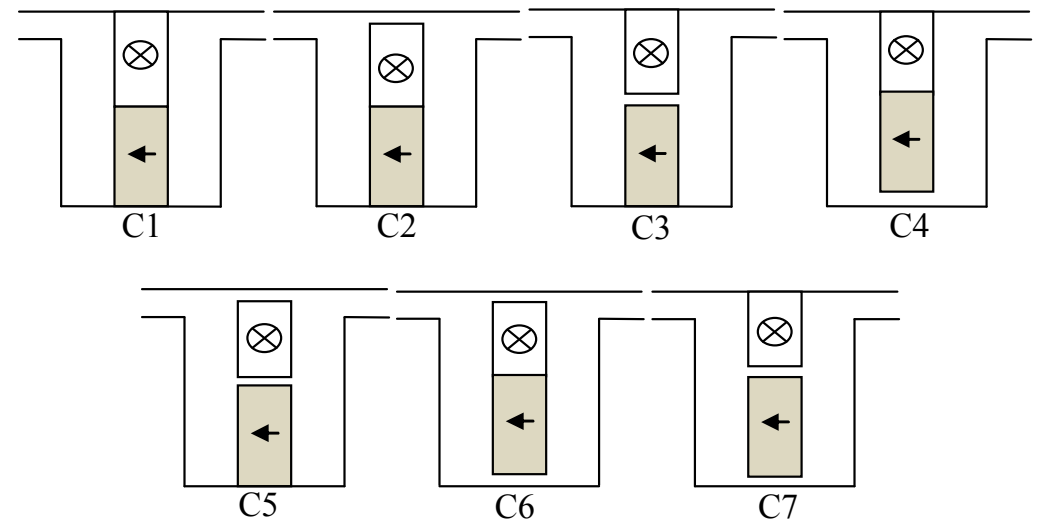

Fig. 2. The arrangement of iron flux bridges

but also can enhance the effectiveness of the FEC with various excitation flux level. Moreover, by increasing the iron flux bridge width in the electrical excitation part, the excitation current utilization will be improved while the excitation loss will be reduced. However, with increasing the thickness of iron flux bridges more PM flux will be short circuited by the iron bridge, which will reduce the utilization ratio of the magnets and machine torque density. The combinations modes of PMs, FEC winding and iron flux bridges will affect the whole performance including reliability (PM demagnetization), PM magnetic short circuit, torque capability and excitation current utilization and excitation loss.

From Fig.1, C1 depicts the initial configuration of C-type HEFSM without iron flux bridge, that inherently affected some flux leakage at the outer stator and inner stator to the air gap. Meanwhile, $\mathrm{C} 2, \mathrm{C} 3$, and $\mathrm{C} 4$ illustrate several arrangements with single iron flux bridge attached between FEC slot and upper layer of stator core, between the FEC slot and PM, and between PM and rotor air gap, respectively. It is noticed that, for $\mathrm{C} 2$ and $\mathrm{C} 3$ conditions, the flux leakage occurs surrounding the PM to air gap, while $\mathrm{C} 4$ consists of flux leakage to air and flux disappear surrounding the outer stator, respectively. Furthermore, C5, C6 and C7 represent, iron flux bridges with two possible combinations between PM, FEC slot and stator, correspondingly. However, under this condition, it is noticed that total flux has been reduced due to flux oppose from one bridge to another, which reduced the total performances. Initially, torque performances of all flux bridge combinations are investigated as depicted in Fig. 3. From the graph, it is clear that the highest torque of approximately $189.6 \mathrm{Nm}$ is achieved for $\mathrm{C} 2$ configuration, while the lowest torque of approximately $174.6 \mathrm{Nm}$ is obtained under $\mathrm{C} 4$ configuration. This is due to the flux leakage and flux cancellation to the air as well as flux disappears to surrounding upper layer of stator core. As $\mathrm{C} 2$ gives the highest torque capability, performances of $\mathrm{C} 2$ configuration such as torque and power characteristics with respect to various $\mathrm{J}_{\mathrm{a}}$ and $\mathrm{J}_{\mathrm{e}}$ conditions are analyzed.

\section{Performance of $\mathrm{C} 2$ design}

The instantaneous torque characteristics at maximum torque condition in which the FEC current density and armature current density are set to $30 \mathrm{~A} / \mathrm{mm}^{2}$ and $30 \mathrm{~A}_{\mathrm{rms}} / \mathrm{mm}^{2}$, respectively are demonstrated in Fig. 4. The average torque reaches $189.6 \mathrm{Nm}$ with peak to peak torque of approximately $47.83 \mathrm{Nm}$. Since the peak-peak torque is higher than required minimum value, estimation of flux linkage which contributes to high cogging torque will be investigated and optimized. Moreover, torque versus $\mathrm{J}_{\mathrm{e}}$ at various $\mathrm{J}_{\mathrm{a}}$ characteristic is represented in Fig. 5. Fig. 5 explains the drive performances of the initial design machine in terms of torque versus FEC current density characteristics of the proposed motor. The graph shows that with increasing in $J_{\mathrm{e}}$, the torque also increase linearly with the same pattern at $0 \mathrm{~A}_{\mathrm{rms}} / \mathrm{mm}^{2}$ until $20 \mathrm{~A}_{\mathrm{rms}} / \mathrm{mm}^{2}$. In the meantime, similar torque characteristic is obtained at $25 \mathrm{~A}_{\mathrm{rms}} / \mathrm{mm}^{2}$ and $30 \mathrm{~A}_{\mathrm{rms}} / \mathrm{mm}^{2}$ in which the torque pattern 


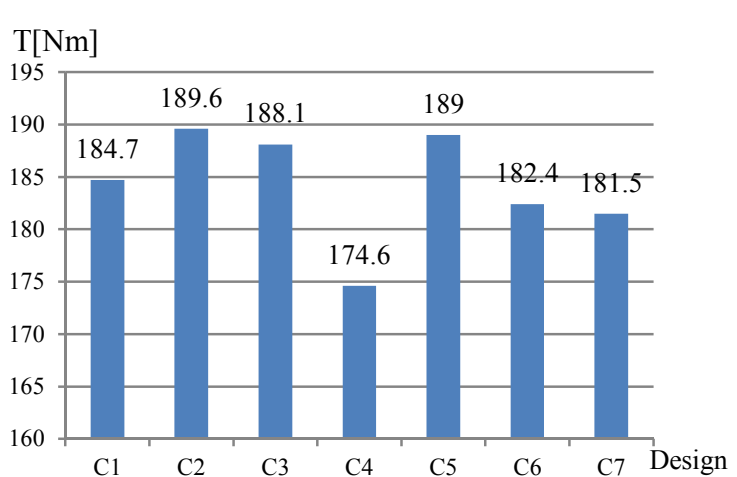

Fig. 3. The maximum torque for all configurations

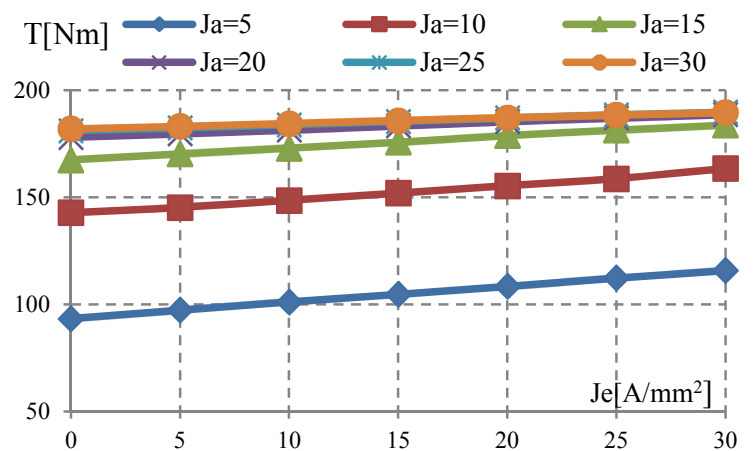

Fig. 5. Torque vs $\mathrm{J}_{\mathrm{e}}$ at various $\mathrm{J}_{\mathrm{a}}$ for $\mathrm{C} 2$

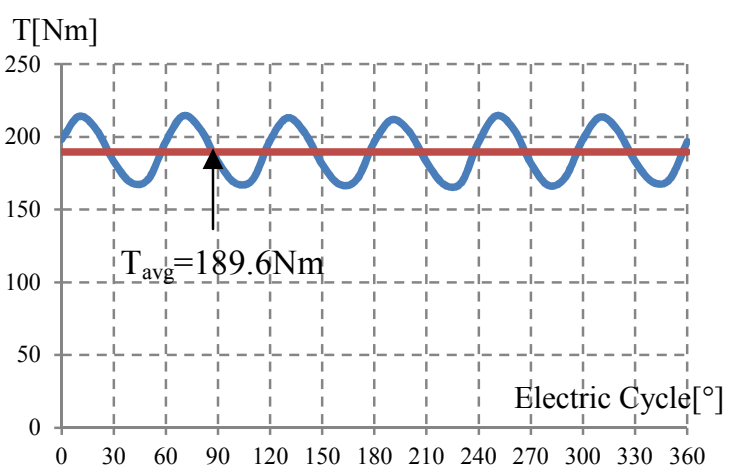

Fig. 4. Instantaneous torque for $\mathrm{C} 2$

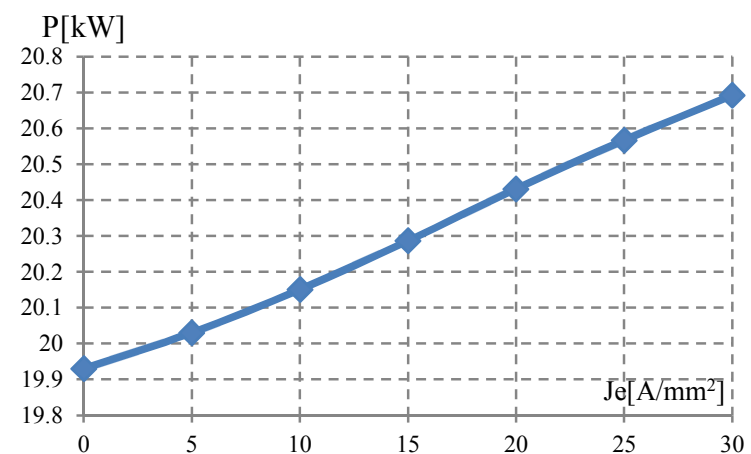

Fig. 6. Power vs various $\mathrm{J}_{\mathrm{e}}$ at maximum $\mathrm{J}_{\mathrm{a}}$ for $\mathrm{C} 2$

is constant. The maximum torque is approximately $189.8 \mathrm{Nm}$ when $\mathrm{J}_{\mathrm{a}}$ of $25 \mathrm{~A}_{\mathrm{rms}} / \mathrm{mm}^{2}$ and $\mathrm{J}_{\mathrm{e}}$ of $30 \mathrm{~A} / \mathrm{mm}^{2}$ are set at the base speed $1042 \mathrm{r} / \mathrm{min}$. This is due to low armature coil flux that limits the force to move the rotor.

Finally, the power versus maximum $\mathrm{J}_{\mathrm{a}}$ at various $\mathrm{J}_{\mathrm{e}}$ is analyzed as depicted in Fig. 6 . It is obvious that the power increased linearly with increasing $\mathrm{J}_{\mathrm{e}}$. The maximum power obtained is approximately $20.7 \mathrm{~kW}$ at maximum $\mathrm{J}_{\mathrm{a}}$ and $\mathrm{J}_{\mathrm{e}}$.

\section{Conclusion}

In this paper, several topologies of the iron flux bridge for C-Type 12S-10P HEFSM have been overviewed and discussed. The main objectives of adding the iron flux bridges to the initial design motor not only can solve the manufacture process but also can enhance the effectiveness of the FEC with various excitation flux level. It can be conclude that configuration 2 with single iron flux bridges located at outer FEC produces higher torque and power with approximately $189.6 \mathrm{Nm}$ and $20.7 \mathrm{~kW}$, respectively when compared with the other design. Lastly, the performance of torque and power have been analyzed and compared. 


\section{References}

[1] Erwan Sulaiman, Takashi Kosaka, Development of High Torque and High Power Density Hybrid Excitation Flux Switching Motor for Traction Drive in Hybrid Electric Vehicles, Energy and Power Engineering, 2013, 5, 446-454, 2013.

[2] D. Fodorean, A. Djerdir, I. A. Viorel and A. Miraoui, "A Double Excited Synchronous Machine for Direct Drive Application-Design and Prototype Tests," IEEE Transac-tions on Energy Conversion, Vol. 22, No. 3, 2007, pp. 656-665.

[3] J. A. Tapia, F. Leonardi and T. A. Lipo, "Consequent- Pole Permanent-Magnet Machine with Extended Field- Weakening Capability," IEEE Transactions on Industry Applications, Vol. 39, No. 6, 2003, pp. 1704-1709.

[4] T. Kosaka and N. Matsui, "Hybrid Excitation Machines with Powdered Iron Core for Electrical Traction Drive Applications," Proceedings of International Conference on Electrical Machines and Systems, Wuhan, China, 17-20 October 2008, pp. 2974-979.

[5] T. Kosaka, M. Sridharbabu, M. Yamamoto and N. Matsui, "Design Studies of Hybrid Excitation Motor for Main Spindle Drive in Machine Tools," IEEE Transactions on Industrial Electronics, Vol. 57, No. 11, 2010, pp. 3807- 3813.

[6] Z. Chen, Y. Sun and Y. Yan, "Static Characteristics of A Novel Hybrid Excitation Doubly Salient Machine," Pro- ceedings of the Eight International Conference on Elec- trical Machines and Systems, Nanjing, 27-29 September 2005, pp. 718-721.

[7] Y. Amara, L. Vido, M. Gabsi, E. Hoang, A. H. Ben Ah- med and M. Lecrivain, "Hybrid Excitation Synchronous Machines: Energy-Efficient Solution for Vehicles Pro- pulsion," IEEE Transactions on Vehicular Technology, Vol. 58, No. 5, 2009, pp. 2137-2149.

[8] NA Jafar, E Sulaiman, "Design Analysis of 12S-10P Hybrid-Excitation Flux-Switching Permanent Magnet Machines for Hybrid Electric Vehicle", Power Engineering and Optimization Conference (PEOCO), Langkawi, 2014.

[9] E. Sulaiman, T. Kosaka, and N. Matsui, "Design and Analysis of High-power/high-torque Density Dual Excitation Switched-Flux Machine for Traction Drive in HEVs", Renewable \& Sustainable Energy Reviews 34, 517-524, 2014.

[10] Y. Amara, L. Vido, M. Gabsi, E. Hoang, M. Lecrivain, and F. Chabot, "Hybrid excitation synchronous machines: Energy efficient solution for vehicle propulsion," IEEE transaction on Vehicular Technology, vol.58, no.5, pp. 2137-2149, 2009.

[11] C. Zhao and Y. Yan, "A review of development of hybrid excitation synchronous machine," in Proc. IEEE Int. Symp. Industrial Electron., Jun. 20-23, 2005, vol. 2, pp. 857-862. 